\title{
In Vitro Modeling of Implantable Cardiac Pacemakers Submitted to Conducted Disturbance
}

\author{
https://doi.org/10.3991/ijoe.v18i01.27289 \\ Karim Djennah, Abdelaziz Ladjimi, Abdesselam Babouri $\left.{ }^{\bowtie}\right)$ \\ Laboratoire de Génie Electrique (LGEG), Université 8 Mai 1945 Guelma, Guelma, Algérie \\ babouri.abdesselam@univ-guelma.dz
}

\begin{abstract}
The work presented describes the modeling of a measurement bench in the presence of an implantable single-chamber pacemaker in vitro subjected to a conducted disturbance. The source of disturbance is a sinusoidal electrical signal with amplitude of $10 \mathrm{~V}$; the frequency ranges studied correspond to the frequencies of the electrical distribution network $(50 / 60 \mathrm{~Hz})$ and to the frequencies of domestic applications $(10 / 25 \mathrm{KHz})$. The numerical simulations were carried out according to two methods, the first based on the finite element method using the Comsol multiphysics software, the second is based on the impedance method. The results obtained by the two methods are in good agreement, and this will allow us to calculate the voltage induced between the ends of the stimulator. These results allowed us to validate the proposed model.
\end{abstract}

Keywords-electromagnetic compatibility, digital modeling, impedance method, low frequency, EMF, cardiac pacemaker

\section{Introduction}

Patients carrying electronic cardiovascular devices (ICEDs), such as pacemakers (PCs), implantable cardiac defibrillators (ICDs) are strongly increased, for example in Europe 547,586 CP and 105,730 ICD were implanted in 2016 [1]. They live in an electromagnetic environment (EMF), of natural but also artificial origin, and the latter is the result of the increased use of electrical energy, necessary to operate surveillance devices, household appliances, and communications...etc. Also medical equipment used in the diagnosis of diseases such as magnetic resonance imaging (MRI) and therapeutic applications in psychiatry and neurology such as transuranic magnetic stimulation (TMS) [17] and electrical stimulation therapy (EST) [2]. This raises questions about the possible effects of exposure to these fields on human health and on the proper functioning of the devices (ICEDs) [21], [22]. The latter proved effective in reducing mortality in patients at high risk of developing ventricular arrhythmias [3]. These two questions have been the subject of several studies over the last decades, in vivo and in vitro. A. Hedjeidj et al in 2002 showed that the exposure of certain PCs to NDEs under specific conditions caused their dysfunction [4]. J Silny et al, in 2014 they showed after the exposure of 110 patients (worn ICDs of 1,2, and 3 chamber) to strong electric and magnetic fields of $50 \mathrm{~Hz}$ ranging up to $30 \mathrm{kv} / \mathrm{m}$, and $2.55 \mathrm{mT}$ in 
some work environments may cause inappropriate detection, which may lead to false detection of atrial/ventricular arrhythmic events [5]. J. Morava and A. Richter in 2020, they showed that ICEDs are subject to incorrect interpretation of electrical signals, because the device does not monitor the shape of the detected signal, according to which it can distinguish between interference and arrhythmias. Thus, the presence of electromagnetic interference signals can also cause temporary modifications to its programming and can easily affect its performance [6]. The MAUDE (The Manufacturer and User Facility Device Experience) database of the US Food and Drug Administration identified 2843 cases of medical device malfunctions induced by EMPs, between January 2010 and March 2017 [7]. T. Campi et al, in 2017 studied the induced effects produced by the application of a wireless energy transfer system (WPT) to recharge the cardiac pacemaker battery to a $\mathrm{CP}$ equipped with a unipolar stimulation lead. The results show the excitation of the stimulation conductor is given by the magnetic field produced by the current coils of the WPT charging system operating at the frequency $\mathrm{f}=0$ at $20 \mathrm{kHz}$ [18], [19], [20].

In addition, studies have not been limited to exposure of ICEDs to EMF due to radiated disturbance only, but many studies have been conducted on exposure to galvanic disturbance, which can be direct or indirect. Contact current can cause interference [8] (developed in the United States in 2002). J P Andretzko et al.[ 10], and babouri et al. [21-22 ] have experimentally studied this type of disturbance on two single-chamber and double-camber CPs types, implanted in a medium equivalent to the biological tissue for the frequencies $(50 \mathrm{~Hz}-500 \mathrm{kHz})$ [9]. The results made it possible to deduce the amplitude of the disturbance signal generating the malfunctions of the CPs tested for a given frequency. F. Egger et al. in 2019, showed that the unilateral application of EST did not interfere with the PM function in any of the configurations $(0 \% ; \mathrm{n}=700)$. In contrast, bilateral pacing (350 configurations in total) caused either ventricular inhibition or a switch to V00 back-up pacing due to electrical interference in 165 cases $(47.1 \%)$ depending on the pacing parameters applied.

Various methods can be used to modeling the distribution of induced potentials in biological tissues, for example the finite difference method (DF) [11], the finite element method (EFM) [12] and the impedance method (IM) [13].

In this work, we carried out numerical simulations in two ways, the first is based on the EFM method, in which we used the Comsol multiphysics software in 2D. The second is the admittances method [14], where we performed a Matlab code. This allowed us to quantify the distribution of the electric potential, in the measurement bench (BM), and to propose an equivalent electric model of the whole, which allowed us to calculate the potential difference between the ends of the cardiac pacemaker " $\mathrm{V}_{\mathrm{eb}}$ ", thus to evaluate the impact of this interference voltage on the operation of the PM.

\section{Presentation of test bed}

The measuring test bed to be modeled is composed of the pacemaker (to simplify the model, we assume a square shape for the case with dimensions of $40 \times 40 \mathrm{~cm}$ ), 
and a probe connected by an insulated conductor wire had a diameter of $2 \mathrm{~mm}$ and a length of about $100 \mathrm{~mm}$. The shielded housing and flat electrode were modeled with perfect conductors (have admittances of the order of $10+6$ ). The assembly is implanted in a tank filled with a homogeneous conductive medium based on gelatin simulating the electrical characteristics of biological tissues [15], and subjected to a conducted disturbance. The disturbance signals are sinusoidal voltages $\left(\mathrm{V}_{\text {gene }}\right)$ of low frequency; the frequencies studied are $50 / 60 \mathrm{~Hz}$ and $10 / 25 \mathrm{KHz}$. We calculated the potential difference $\mathrm{V}_{\mathrm{eb}}$ between the housing and the end of the probe generated by the disturbance signals. These are applied between two conductive copper plates at the ends of the tank (Figure 1).
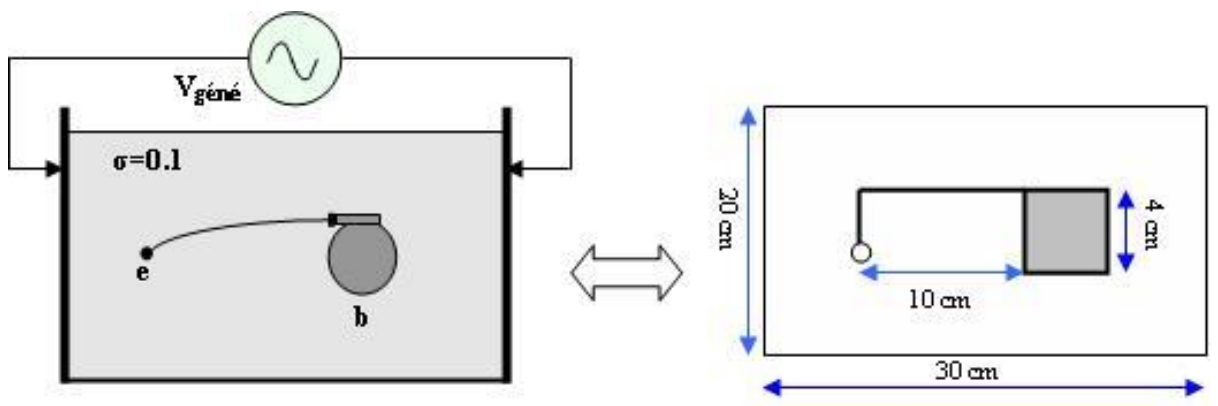

Fig. 1. Test bed in conducted disturbance

\section{Methods description}

\subsection{Admittance method}

The impedance method [14] consists in constructing an electrical network representative of the environment. For this, the studied medium is broken down into square cells in the case of a $2 \mathrm{D}$ representation or a parallelepiped in $3 \mathrm{D}$ representation (Figure 2.). Each vertex of the cells is represented by a node and each two edges carry impedance:

$$
Y_{n}^{i, j, k}=\frac{\delta_{m} \delta_{p}}{\delta_{n}}\left(\sigma_{n}(i, j, k)+j \omega \varepsilon_{n}(i, j, k)\right)
$$

$\delta_{m} \delta_{p} \delta_{n}$ : Dimensions of the elementary parallelepiped for the three directions of space; 'n' represents the considered direction ( $\mathrm{x}, \mathrm{y}$ ou $\mathrm{z}$ ), and $\sigma_{n}(i, j, k), \varepsilon_{n}(i, j, k)$ represent the conductivity and permittivity in the direction of ' $n$ '.

In quasi-stationary regime [16], and for the studied frequencies $50 / 60 \mathrm{~Hz}$ and 10/25 $\mathrm{KHz}$.

$\frac{\omega \varepsilon_{n}(i, j, k)}{\sigma_{n}(i, j, k)} \ll 1$ So the equation (1) is written:

$$
Y_{n}^{i, j, k}=\frac{\delta_{m} \delta_{p}}{\delta_{n}}\left(\sigma_{n}(i, j, k)\right)
$$




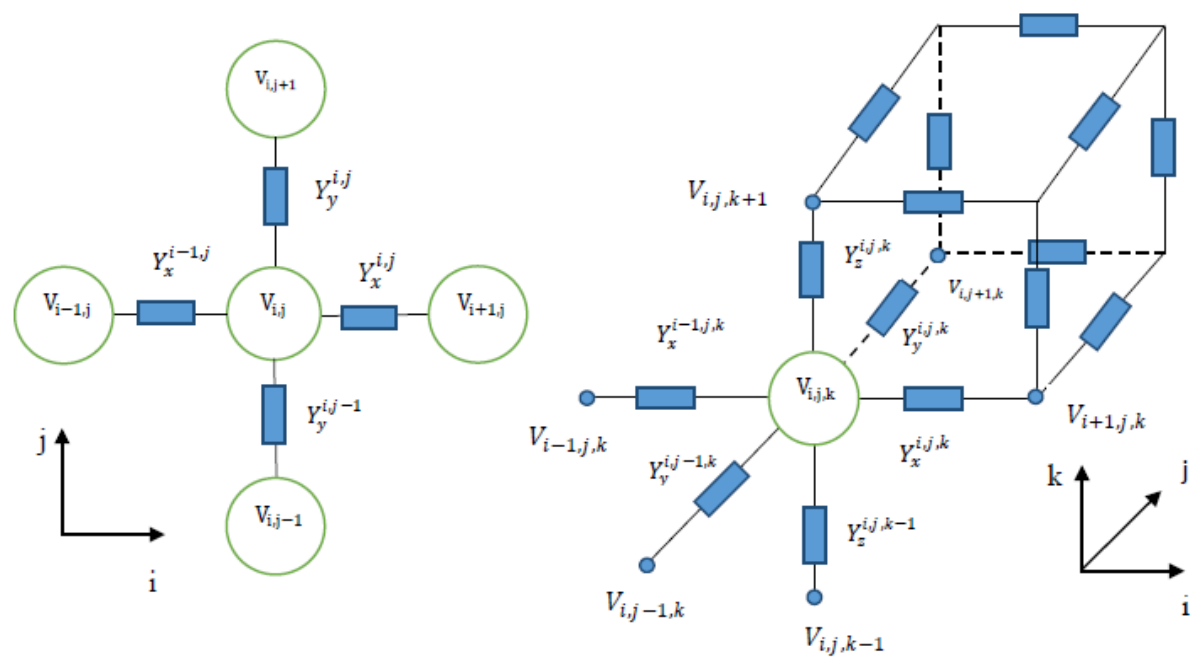

Fig. 2. Mesh of the medium in $2 \mathrm{D}$ and $3 \mathrm{D}$

\subsection{Electrical potentials calculation}

The electrical potentials are calculated at the different nodes in the network, the value of the potential at the point of coordinates $(\mathrm{i}, \mathrm{j}, \mathrm{k})$ is obtained from the adjacent potentials using Hillman's theorem (Figure 3):

$$
V_{(i, j, k)}=\frac{\sum_{k=1}^{3} \sum_{L=0}^{1} V_{r} Y_{m}^{c}}{\sum_{k=1}^{3} \Sigma_{L=0}^{1} Y_{m}^{c}}
$$

The indices c, $\mathrm{r}$ determined according to the relations summarized in table 1 .

Table 1. Index values $r$ and $c$

\begin{tabular}{|c|c|c|c|}
\hline $\mathbf{k}$ & $\mathbf{r}$ & $\mathbf{c}$ & $\mathbf{n}$ \\
\hline 1 & $(\mathrm{i}-1+2 \mathrm{~L}, \mathrm{j}, \mathrm{k})$ & $(\mathrm{i}-1+\mathrm{L}, \mathrm{j}, \mathrm{k})$ & $\mathrm{x}$ \\
\hline 2 & $(\mathrm{i}, \mathrm{j}-1+2 \mathrm{~L}, \mathrm{k})$ & $(\mathrm{i}, \mathrm{j}-1+\mathrm{L}, \mathrm{k})$ & $\mathrm{y}$ \\
\hline 3 & $(\mathrm{i}, \mathrm{j}, \mathrm{k}-1+2 \mathrm{~L})$ & $(\mathrm{i}, \mathrm{j}, \mathrm{k}-1+\mathrm{L})$ & $\mathrm{z}$ \\
\hline
\end{tabular}

For the 2D application, equation (3) is:

$$
V_{i, j}=\frac{V_{i+1, j} \cdot Y_{y}^{i-1, j}+V_{i, j+1} \cdot Y_{x}^{i, j}+V_{i-1, j} \cdot Y_{y}^{i, j}+V_{i, j-1} \cdot Y_{x}^{i, j-1}}{Y_{y}^{i-1, j}+Y_{x}^{i, j}+Y_{y}^{i, j}+Y_{x}^{i, j-1}}
$$

The calculation of the distribution of $\mathrm{N}$ potentials in the test bed went through 3 stages. The first one is the mesh of the test bed, adopting a mesh ( $2 \mathrm{~mm}$ pitch) equivalent to the dimension of the probe (Figure 3). The second consists in constructing a matrix comprising approximately $\mathrm{N}$ terms $(151 \times 101=15251)$. 


$$
\left[\begin{array}{ccc}
m_{1,1} & \cdots & m_{1, N} \\
\vdots & \ddots & \vdots \\
m_{1, N} & \cdots & m_{N, N}
\end{array}\right] \times\left[\begin{array}{c}
V_{1} \\
\vdots \\
V_{101} \\
V_{102} \\
\vdots \\
V_{15251}
\end{array}\right]=\left[\begin{array}{c}
V_{s} \\
\vdots \\
V_{s} \\
0 \\
\vdots \\
0
\end{array}\right]
$$

Such as:

$\mathrm{M}$ : represents a square matrix $(\mathrm{N} * \mathrm{~N})$, whose elements "m_ $(\mathrm{N}, \mathrm{N})$ " are numerical coefficients depending on the $\mathrm{N}$ unknowns $\left(\mathrm{V}_{-}(1), \ldots \mathrm{V}_{-} \mathrm{N}\right)$, involved in the equations of the system (6).

$\mathrm{X}$ : Represents the column-vector of the unknowns.

b: represents the column vector which involves the boundary conditions.

The third step consists in solving the linear system of equation (6), using the (cause-Seidel) method, with MATLAB R2016 a software. Convergence is fast

$$
\left\{\begin{array}{ccc}
m_{1,1} * v_{1}+\cdots & +m_{1, N} * v_{N} & =V_{s} \\
& \vdots & \\
m_{101,1} * v_{1}+\cdots & +m_{101, N} * v_{N} & =V_{s} \\
m_{102,1} * v_{1}+\cdots & +m_{102, N} * v_{N} & =0 \\
& \vdots & \\
m_{N, 1} * v_{1}+\cdots & +m_{N, N} * v_{N} & =0
\end{array}\right.
$$

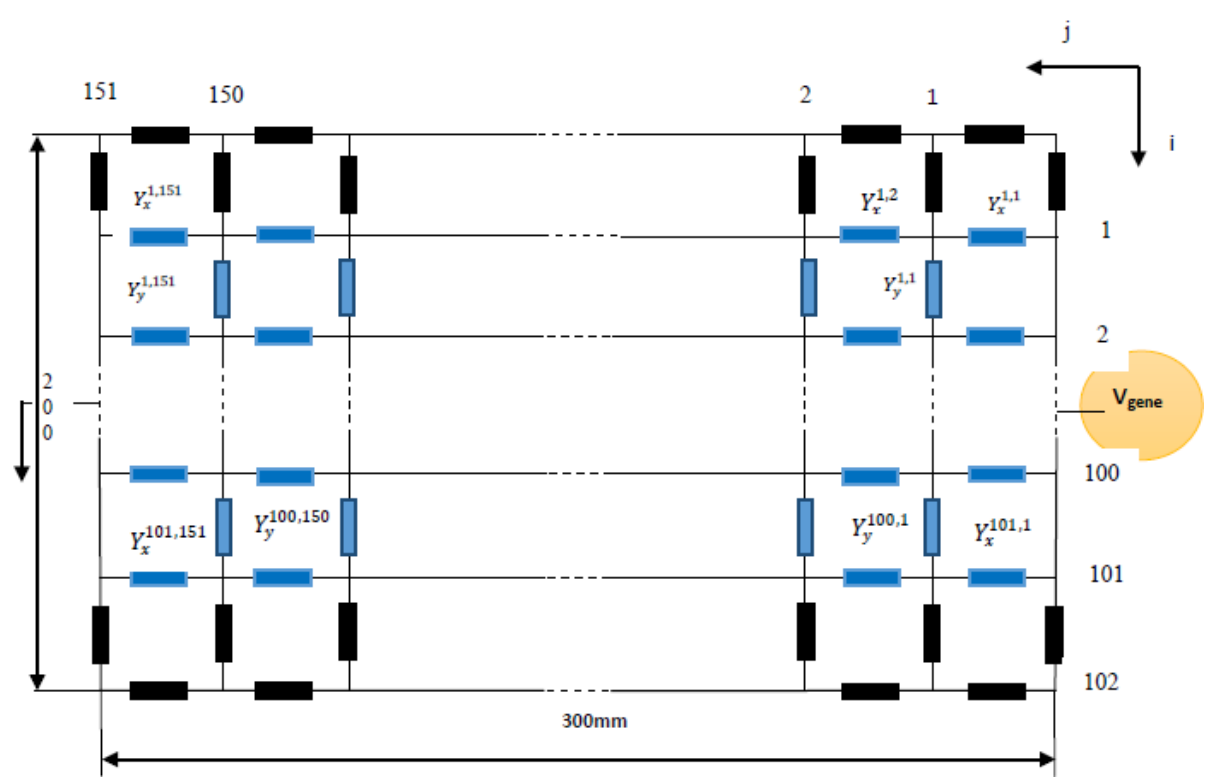

Fig. 3. Mesh of the test bed, application of the admittance method 


\subsection{Numerical modeling}

The numerical simulation is carried out by the Comsol multiphysics software in 2D, with a quasi-static approximation in weak current; this one used the finite element method. Figure (4), illustrates the mesh of the elements of the measurement bench model. The number of meshes is 20277 with a minimum size near the probe and 1 $\mathrm{mm}$.

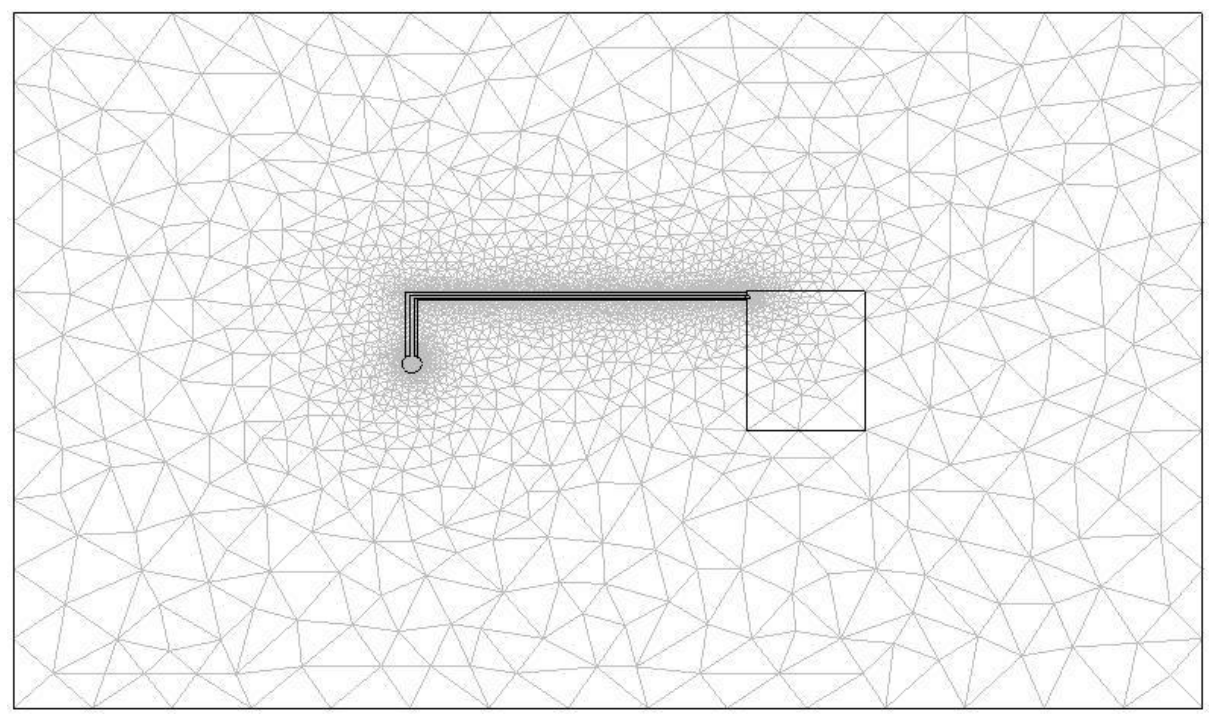

Fig. 4. Mesh of the measuring bench, application of the FE method

\section{$4 \quad$ Results analysis}

Figures (5), (6) and (7) respectively show the distribution by the two methods and the contour of the electrical potential in 2D in the measurement bench (Tank + cardiac pacemaker), for a disturbance signal of $10 \mathrm{~V}$ amplitude and a frequency of $10 \mathrm{KHz}$. These two figures show the linear distribution of electric potential except inside the housing and at the end of the probe where the electric potential is constant. They also show the variations in the electric potential contour around the housing and at the end of the probe. In the rest of the simulation domain, the contours of the electric potential are uniform and constant lines with respect to the y-axis. Figure (8) shows the distribution of the electric field in the measurement bench for the same disturbance signal, the vector field is disturbed near the housing and at the end of the probe. With these results we have shown the effects of electrical contact on the functioning of pacemakers. 


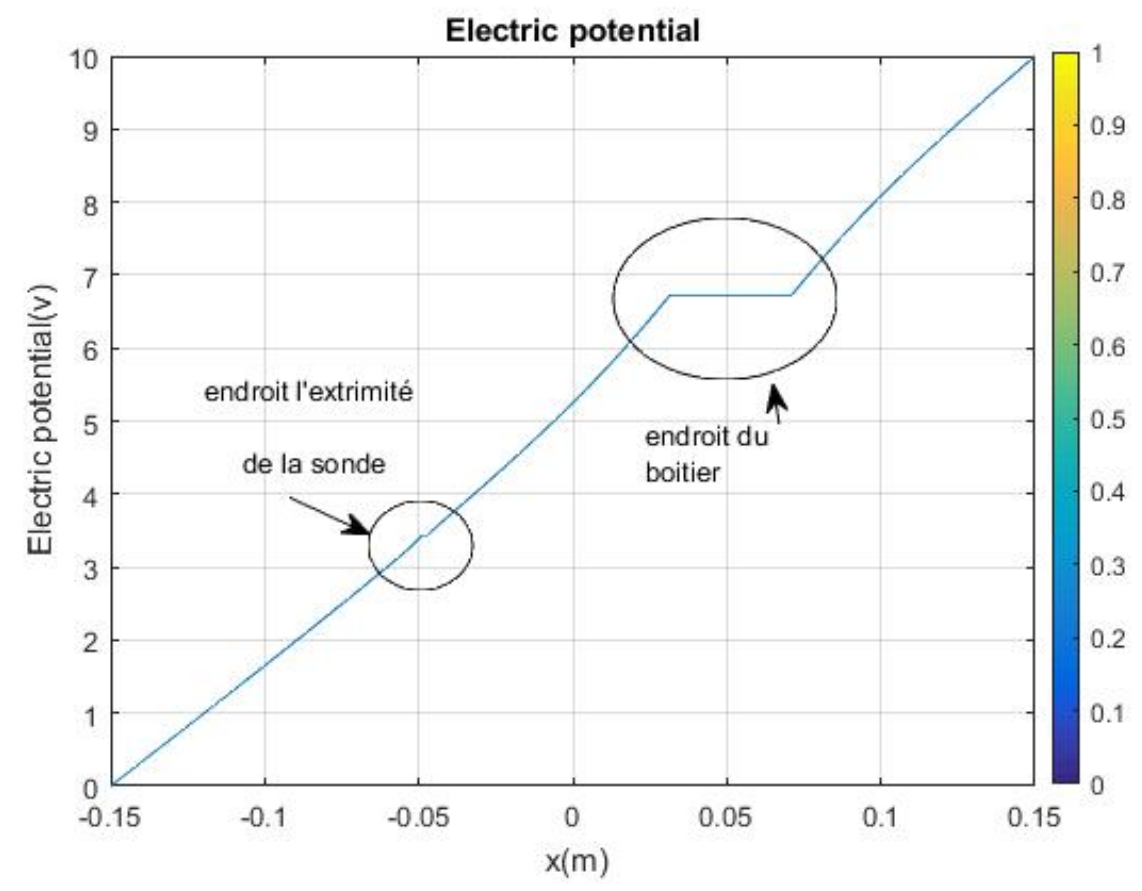

Fig. 5. Profile of electric potential-method of admittances

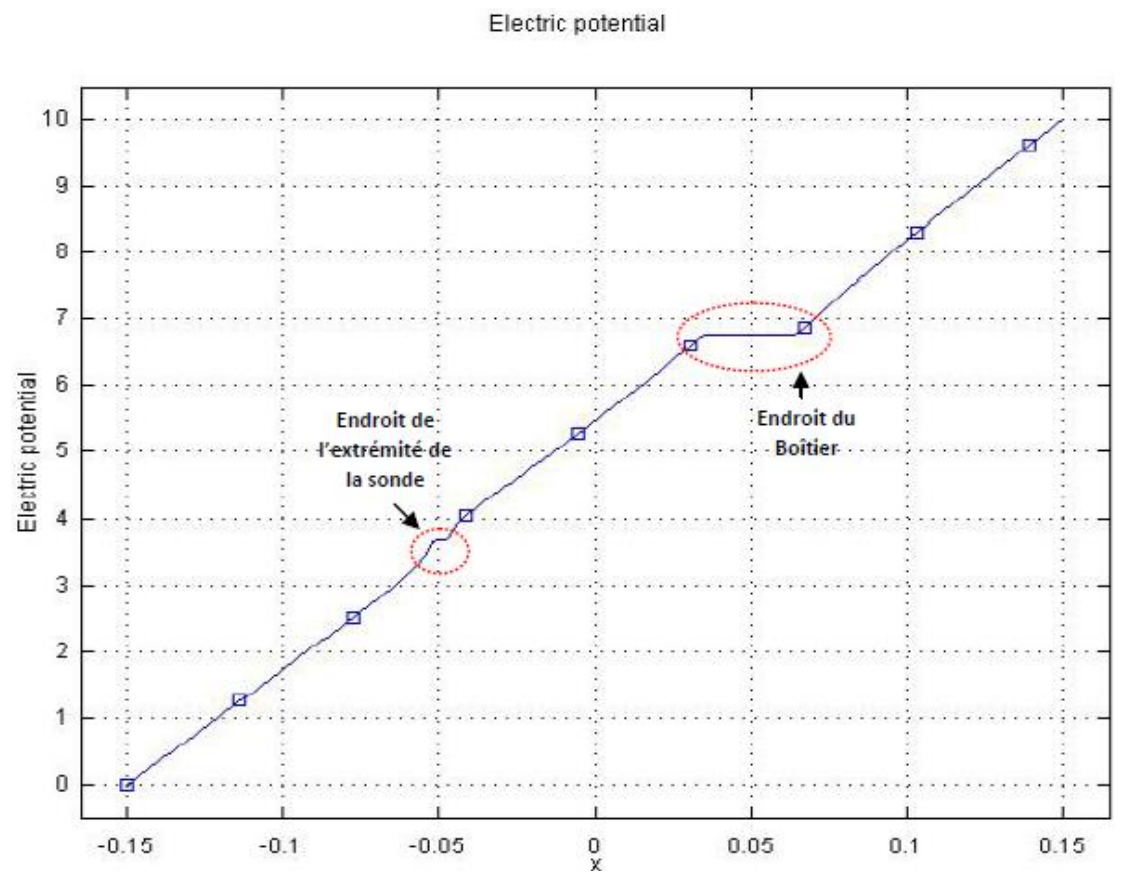

Fig. 6. Profile of electric potential-EF Method 


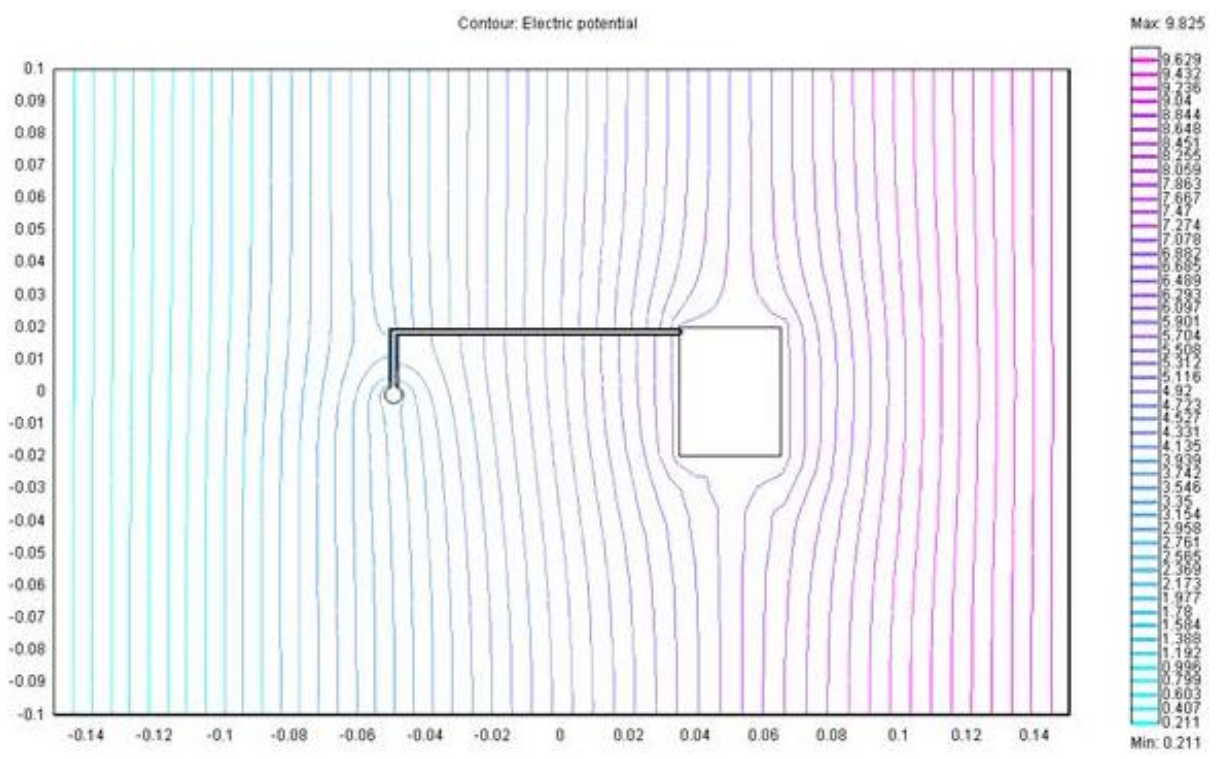

Fig. 7. Contour of the electric potential-F $=10 \mathrm{KHz}, \mathrm{V}=10 \mathrm{~V}, \mathrm{Ri}=550 \mathrm{Ohm}$

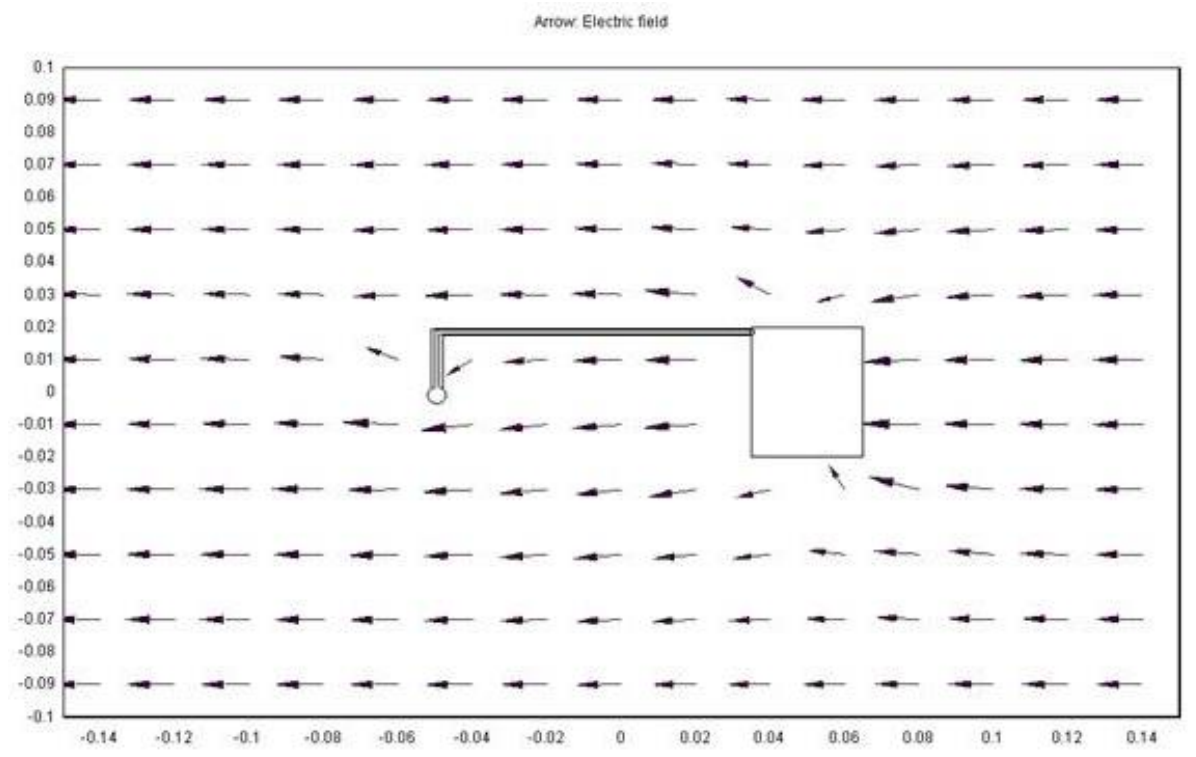

Fig. 8. Representation of the electric field $-\mathrm{F}=10 \mathrm{KHz}, \mathrm{V}=10 \mathrm{~V}, \mathrm{Ri}=550 \mathrm{Ohm}$

Figures 9, 10, 11, 12 shows the variations of electric potential $\mathrm{V}_{\mathrm{eb}}$ (housing-probe) as a function of the applied potential $\mathrm{Vg}$ for the four frequencies studied. The four curves show a linear variation with a close slope which is almost identical for each 
frequency. These results show that the effect of frequency is very small. We obtain for the four frequencies:

- $\left|\mathbf{V}_{\text {eb }}\right|=\mathbf{0 . 3 0 7 5}\left|\mathbf{V}_{\mathbf{g}}\right|$ at the frequency: $\mathrm{F}=10 \mathrm{KHz}$

- $\mathbf{V}_{\text {eb }}=\mathbf{0 . 2 9 4 7} \mid \mathbf{V}_{\mathbf{g}}$ at the frequency: $\mathrm{F}=25 \mathrm{KHz}$

- $\left|\mathbf{V}_{\text {eb }}\right|=0.32\left|\mathbf{V}_{\mathbf{g}}\right|$ at the frequency: $\mathrm{F}=50 \mathrm{~Hz}$ and $60 \mathrm{~Hz}$

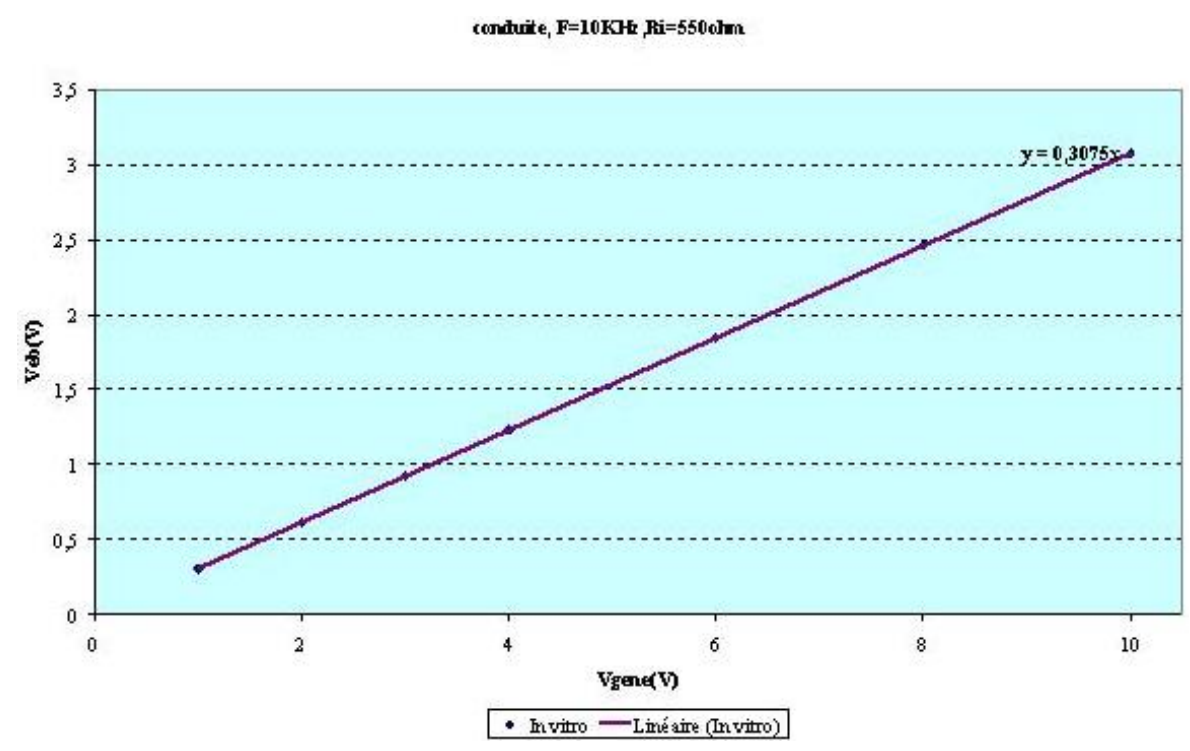

Fig. 9. Electric potential Veb as a function of the applied electric potential $\mathrm{Vg}(\mathrm{F}=10 \mathrm{KHz})$

conduit $\mathrm{F}=25 \mathrm{KHz}$, $\mathrm{Bi}=250 \mathrm{Ohm}$

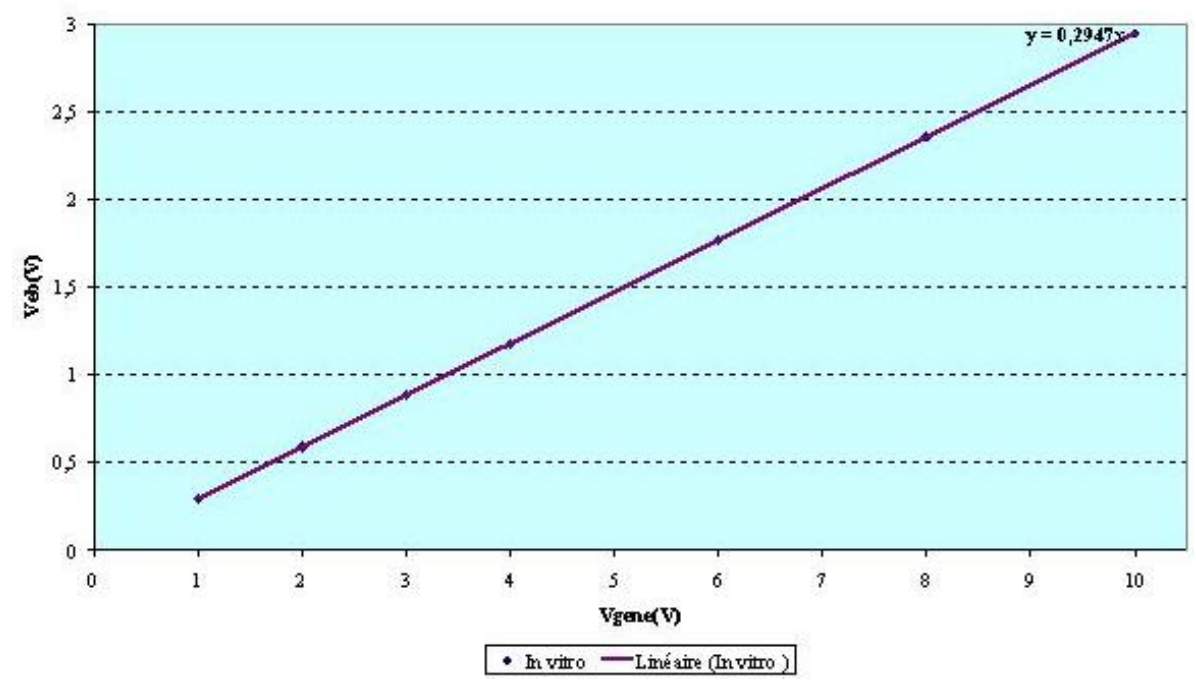

Fig. 10. Electric potential Veb as a function of the applied electric potential $\mathrm{Vg}(\mathrm{F}=25 \mathrm{KHz})$ 


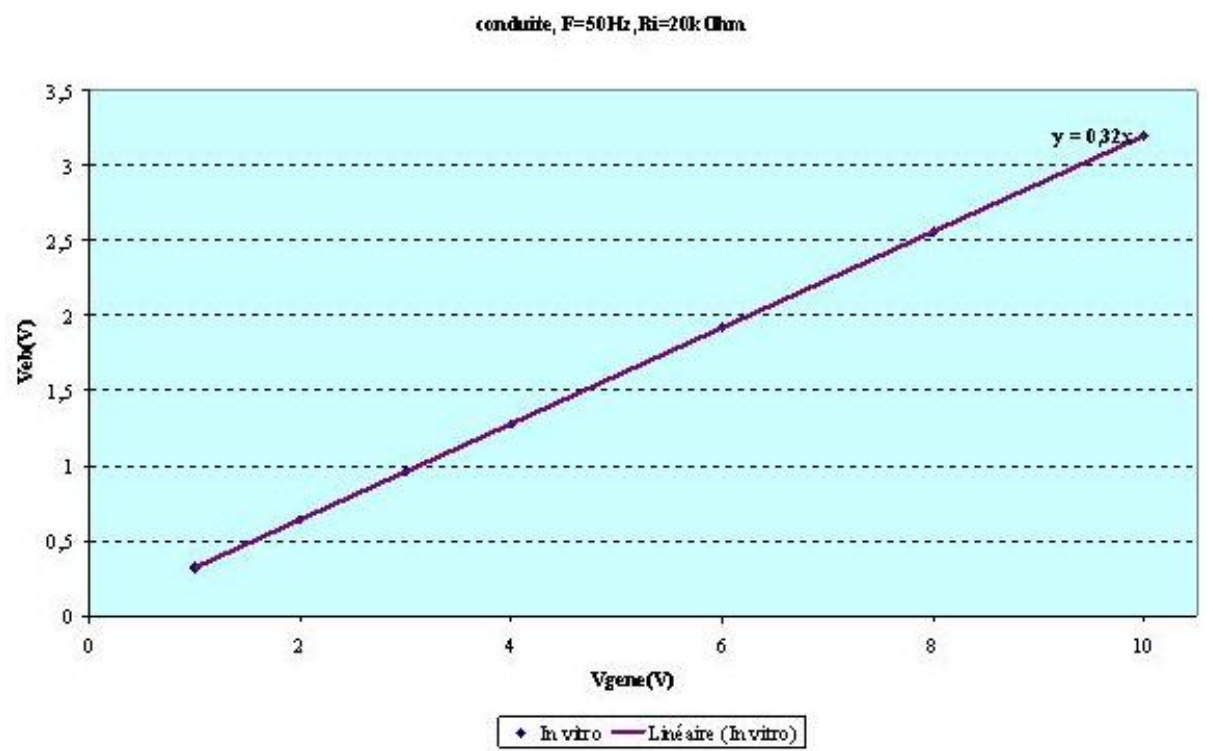

Fig. 11. Electric potential Veb as a function of the applied electric potential $\mathrm{Vg}(\mathrm{F}=50 \mathrm{~Hz})$

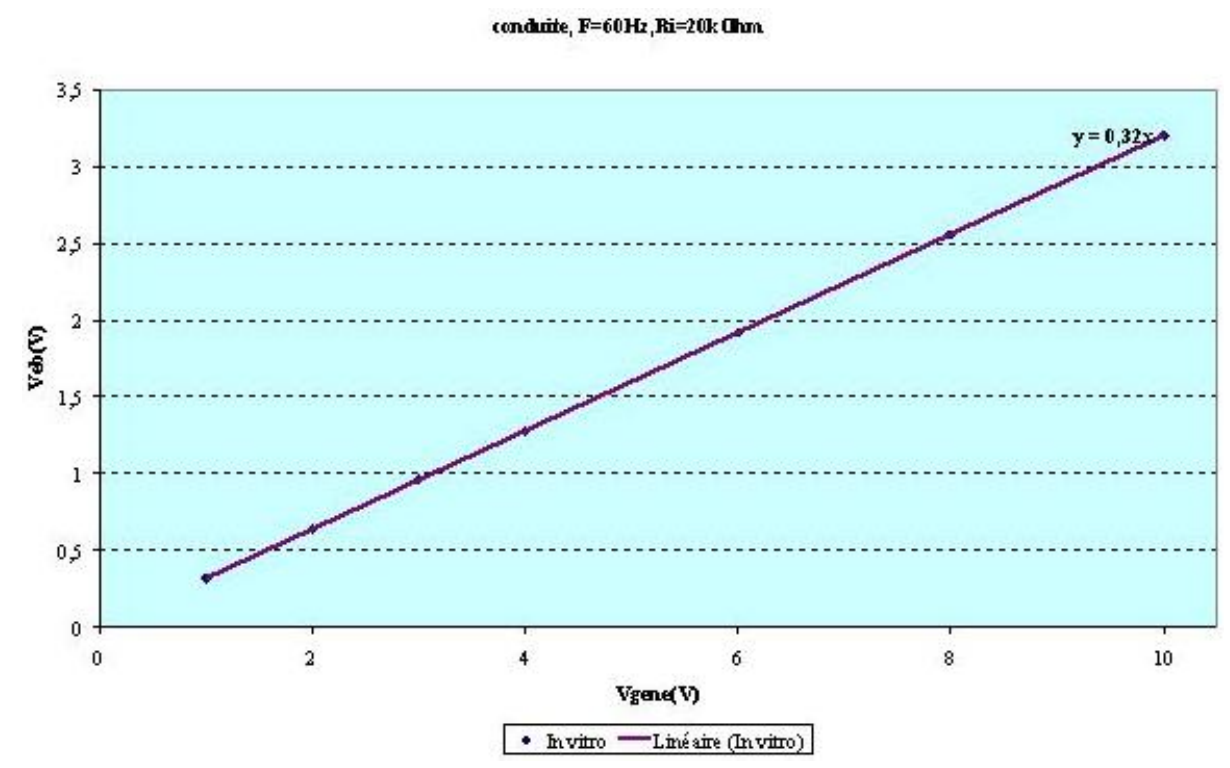

Fig. 12. Electric potential Veb as a function of the applied electric potential $\mathrm{Vg}(\mathrm{F}=60 \mathrm{~Hz})$

\subsection{Electrical equivalent model}

According to the results obtained by the two methods, the measurement bench can be represented by an electrical model made up of two resistances $\mathrm{R}$ and $\mathrm{Ri}$ which 
represent respectively the charge of the interface (middle) and the internal resistance of the cardiac pacemaker with its probe (Figure 13). We can calculate the potential electric through the proposed model by the following equation:

$$
V_{e b}=V_{g e n e} \times \frac{R_{i}}{R_{i}+R}
$$

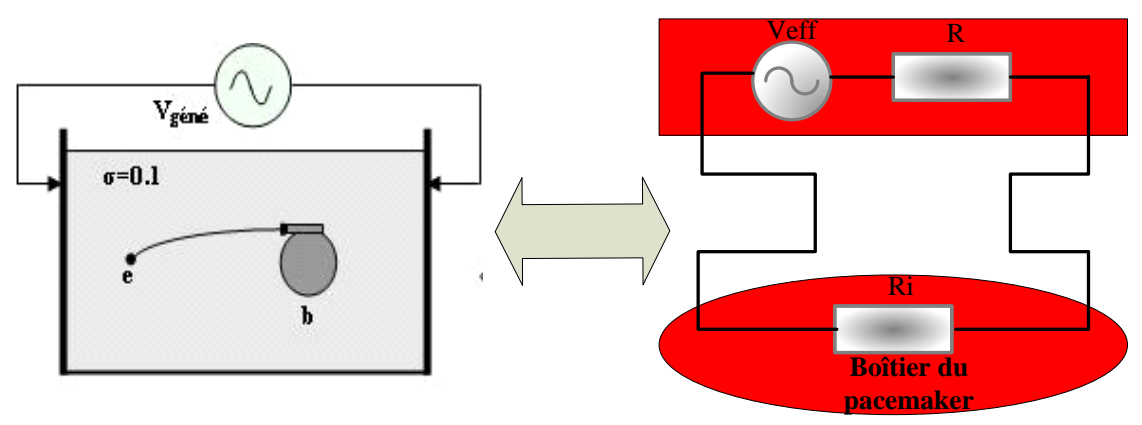

Fig. 13. Equivalent circuit pacemaker —in vitro model

\section{Conclusion}

In this article, two different methods have been applied to study the behavior of cardiac pacemakers subject to conducted disturbances. The first based on the finite element method using ComSol multihysical software, the second based on the impedance method. A comparative study was conducted in which each method was analyzed in order to propose a In Vitro equivalent electrical model indeed; the results of the electrical potential obtained with the two methods are in very good agreement. In the end, it was found that the applied approach is very effective in studying, characterizing and predicting electromagnetic interference in Comparison with international standards. The proposed model is valid for other devices (medical implants, industrial component ... etc.)

\section{Acknowledgment}

This work is supported by the Directorate General for Scientific Research and Technological Development (DG-RSDT) of Algeria, as part of research project (PRFU N ${ }^{\circ}$ A01L07UN2401201 90001).

\section{$7 \quad$ References}

[1] M.J. Pekka Raatikainen, David O. Arnar, Bela Merkely, Jens Cosedis Nielsen, Gerhard Hindricks, Hein Heidbuchel, John Camm."A decade of information on the use of cardiac implantable electronic devices and interventional electrophysiological procedures in the 
European Society of Cardiology Countries2017 Report from the European Heart Rhythm Association“EP Europace, Volume 19, Issue suppl_2, August 2017, Pages ii1-ii90. https://doi.org/10.1093/europace/eux258

[2] Florian Egger, Christian Hofer, Fabian P. Hammerle, Stefan Löfler, Michael Nürnberg, Lukas Fiedler, Ruxandra Kriz, Helmut Kern, Kurt Huber. "Influence of electrical stimulation therapy on permanent pacemaker function"Springer-Verlag GmbH Austria, part of Springer Nature 2019. https://doi.org/10.1007/s00508-019-1494-5

[3] Bristow MR, Saxon LA, Boehmer J, Krueger S, Kass DA, De Marco T, Carson P, DiCarlo L, DeMets D, White BG, DeVries DW, Feldman AM, Comparison of Medical Therapy P, Defibrillation in Heart Failure I (2004) Cardiac-resynchronization therapy with or without an implantable defibrillator in advanced chronic heart failure. N Engl J Med 350:21402150. https://doi.org/10.1056/nejmoa032423

[4] Hedjiedj A, Goeury C and Nadi M "A methodological approach for the characterization of cardiac pacemaker immunity to low frequency interferences: case of $50 \mathrm{~Hz}, 60 \mathrm{~Hz}, 10 \mathrm{kHz}$ and $25 \mathrm{kHz}$ led disruptions"Eng, vol. 26, no. 5, pp.223-227, 2002. https://doi.org/10.1080/ 03091900210156896

[5] Scholten A and Silny J 2001. The interference threshold of cardiac pacemakers in electric $50 \mathrm{~Hz}$ fields J. Med. Eng. Technol. 25 1-11. https://doi.org/10.1080/03091900010025893

[6] Jan Morava, Aleš Richter"the change of cardiostimulation device programming due to detection of electromagnetic interference“ Lekar a technika - Clinician and Technology 2020, vol. 50(2), pp. 65-68. https://doi.org/10.14311/ctj.2020.2.04

[7] Manufacturer and User Facility Device Experience (MAUDE).

[8] http://www.accessdata.fda.gov/scripts/cdrh/cfdocs/cfMAUDE/search.CFM (31 May 2017, date last accessed).

[9] Pierre-Paul Barbier, "Etude et justification des courants de contact induits par les lignes à haute tension dans le parc résidentiel belge et leurs incidences sur la population " 2014

[10] J P Andretzko, A Hedjiedj and L Guendouz, "Calculation of the induced voltage at the terminals of cardiac pacemakers submitted to conducted disturbances,"Eng., vol.28, no.4, pp. 363-372, march 2007. https://doi.org/10.1088/0967-3334/28/4/003

[11] Florian Egger, Christian Hofer, Fabian P. Hammerle, Stefan Löfler, Michael Nürnberg, Lukas Fiedler, Ruxandra Kriz, Helmut Kern, Kurt Huber "Influence of electrical stimulation therapy on permanent pacemaker function "Wien Klin Wochenschr (2019) 131:313320. https://doi.org/10.1007/s00508-019-1494-5

[12] M. Sekino and S. Ueno, "FEM-based determination of optimum current distribution in transcranial magnetic stimulation as an alternative to elec-troconvulsive therapy," IEEE Trans. Magn., vol. 40, no. 4, pp. 2167-2169, Jul. 2004. https://doi.org/10.1109/tmag.2004. $\underline{828982}$

[13] M. Nadeem, T. Thorlin, O. P. Gandhi, and M. Persson, "Computation of electric and magnetic stimulation in human head using the 3D impedance method," IEEE Trans. Biomed. Eng., vol. 50, no. 7, pp. 900-907, Jul. 2003. https://doi.org/10.1109/tbme.2003.813548

[14] Armitage D W, Le Ven H H and Pethig R 1983. Radiofrequency induced hyperthermia: computer simulation of specific absorption rate distribution using realistic anatomical models Phys. Med. Biol. 28 31-42. https://doi.org/10.1088/0031-9155/28/1/003

[15] Goeury C, Hedjiedj A., Nadi M., 2001, Gel conducter por la simulation de la conductivité électrique des tissus humains entre $50 \mathrm{~Hz}$ et $500 \mathrm{KHz}$, ITBM-RBM Vol.22, 371-7. https://doi.org/10.1016/s1297-9562(01)90012-9

[16] plesey 1969. "Electromagnetic Noise Interference and Compatibility“,Publisher November 1975 Copyright C) AGARD 1975. 
[17] P. Vacher, A. Charlanes, C. Chesnel, A. Pagès, C. Malot, F. Le Breton, G. Amarenco, P. Manceau"Intérêt de la stimulation transcrânienne dans les troubles pelvi-périnéaux" progrès en urologie, vol, 29, pp. 349-359, avril 2019. https://doi.org/10.1016/j.purol.2019. $\underline{03.001}$

[18] T. Campi, S. Cruciani, V. De Santis, and M. Feliziani, "EMF safety and thermal aspects in a pacemaker equipped with a wireless power transfer system working at low frequency," IEEE Trans. Microw. Theory Techn., vol. 64, no. 2, pp. 375-382, Feb. 2016. https://doi. org/10.1109/tmtt.2015.2514087

[19] T. Campi, S. Cruciani, F. Palandrani, V. De Santis, A. Hirata, and M. Feliziani, "Wireless power transfer charging system for AIMDs and pacemakers," IEEE Trans. Microw. Theory Techn., vol. 64, no. 2, pp. 633-642, Feb. 2016. https://doi.org/10.1109/tmtt.2015.2511 $\underline{011}$

[20] T. Campi, S. Cruciani, V. De Santis, F. Palandrani, F. Maradei, and M. Feliziani, "Induced Effects in a Pacemaker Equipped With a Wireless Power Transfer Charging System,' IEEE transactions on magnetics, vol. 53, no. 6, june 2017. https://doi.org/10.1109/cefc.2016. 7816069

[21] A. Babouri, A. Hedjiedj, L. Guendouz, J.P. Andretzko, The behaviour of dual chamber pacemakers exposed to a conducted low frequency disruptive signal, Physiol. Meas, 27, pp. 725-736, 2006. https://doi.org/10.1088/0967-3334/27/8/007

[22] A. Babouri, A. Hedjeidj, L. Guendouz. Experimental and Theoretical Investigation of Implantable Cardiac Pacemaker Exposed to Low Frequency Magnetic Field, Journal of Clinical Monitoring and Computing, 23, pp.63-73, 2009. https://doi.org/10.1007/s10877-0089157-5

\section{Authors}

Karim Djennah is Phd student in LGEG Laboratory, Université 8 Mai 1945 Guelma, BP. 401, Guelma, 24000, Algérie (Email: djennah.karim@univ-guelma.dz).

Abdelaziz Ladjimi is associate professor in LGEG Laboratory, Université 8 Mai 1945 Guelma, BP. 401, Guelma, 24000, Algérie (Email: ladjimi.abdelaziz@univ-gue lma.dz).

Abdesselam Babouri is member of the International Association of Online Engineering (IAOE, Member ID: 10146) and member of e-engineering alliance. He is Full Professor in the Department of Electrical Engineering at the University of Guelma, Algeria. He received a doctor-ate degree in Electronic from the University of Nancy, France in 2007. Member and Team Leader of Electromagnetic compatibility and biomedical systems at the LGEG Laboratory. He has authored more than 60 papers in international journal or conference proceedings. His main research interests are sensor networks and biomedical applications, VLC, clinical evaluation of pacemaker systems, e-learning and remote laboratories.

Article submitted 2021-10-04. Resubmitted 2021-11-06. Final acceptance 2021-11-08. Final version published as submitted by the authors. 